\title{
Quantitative studies on taste preference in pigs
}

\section{By B. A. Baldwin, ARC Institute of Animal Physiology, Babraham, Cambridge $C B 24 A T$}

The sense of taste is an important factor in determining the selection of food by animals. As has been pointed out by Le Magnen (1971), the term 'palatability' of a food is based upon the observed feeding response when an animal is offered the food. The palatability of a food is a response to the effect of that food upon several different sensory systems in the mouth simultaneously, the main ones being the chemosensory receptors (olfaction and taste) and also the touch and temperature receptors. In the past the role of taste in the palatability of a food has been emphasized, but the importance of olfaction is now being recognized (Le Magnen, 1971; Larue \& Le Magnen, 1974). The increasing amount of research concerned with the role of the chemical senses in the biology of animals and man is indicated by recent symposia (Zotterman, 1963; Hayashi, 1967; Pfaffman, 1969).

In contrast to the extensive literature concerned with taste preferences in laboratory animals, particularly rats, relatively little work has been done on taste preferences in farm animals. Taste preferences in calves have been studied by Bell \& Williams (1959), Kare \& Ficken (1963) and Goatcher \& Church (1970c, d), in sheep by Goatcher \& Church (1970a,b,c,d) and in goats by Bell (1959) and Goatcher \& Church $(1970 c, d)$. Taste preferences in pigs, using substances in solution as the test stimuli, have been studied by Kare, Pond \& Cambell (1965) and Kennedy \& Baldwin (1972).

Following the early observations of Nelson, Hazel, Moore, Maddock, Ashton, Culbertson \& Catron (1953), there has been considerable interest in the ability of sweetening agents to increase the palatability of pig foods and although they were not primarily concerned with taste preference, some of these studies are mentioned below.

Notzold, Becker, Terrill \& Jensen (1955) carried out experiments in which saccharin and dried cane molasses were used as additives to the rations of fattening pigs and found that, at levels of 0.3 or $1 \mathrm{~g}$ saccharin $/ \mathrm{kg}$, no significant effect was observed on food consumption, rate of body-weight gain or food conversion efficiency. Similarly, dried cane molasses fed at a rate of $72 \mathrm{~g} / \mathrm{kg}$ had no effect on these indices. However, it was shown, in a palatability trial, that pigs displayed a preference for shelled maize treated with $0.5 \mathrm{~g}$ saccharin $/ \mathrm{kg}$ during the first half of a $55 \mathrm{~d}$ feeding period.

In experiments designed to compare the effects of adding refined cane sugar, invert cane molasses and unrefined cane sugar to starter rations for early-weaned pigs, Diaz, Speer, Ashton, Liu \& Catron (1956) found that increased levels of 
refined and unrefined cane sugar, but not of sugar from invert cane molasses, improved body-weight gain and food conversion efficiency.

The effect of adding saccharin on the consumption of starter rations by baby pigs was studied by Aldinger, Speer, Hays \& Catron (1959). They observed that their pigs preferred a diet containing some saccharin. In a recent study concerned with palatability comparisons of diets for early-weaned pigs, Wahlstrom, Hauser \& Libal (1974) concluded that young pigs consumed more of a diet containing sugar than of one which did not, when both diets were available at all times, but, if only one diet were available at a time, the addition of sugar did not greatly increase consumption.

The first quantitative work on the sense of taste in pigs was carried out by Kare et al. $(1965)$, who used the two-choice method in which pigs were presented with a choice of two glass drinking buckets, one of which contained water and the other the solution being tested. Care was taken, by alternating the position of the buckets, to avoid position preferences. The amount of water and test solution consumed in a 24 h period was noted. They used young pigs, fed ad lib., and they examined the pigs' taste responses to saccharin, sucrose, glucose and lactose. In all studies of this type it is conventional to determine the percentage preference for the test substance, and this is defined as:

$$
\text { Percentage preference }=\frac{\text { volume of test solution consumed }}{\text { total fluid volume consumed }} \times \text { roo. }
$$

In order to facilitate comparisons with other published work, the following terms will be used in accordance with the work of Goatcher \& Church $(1970 a, b, c, d): 60-80 \%$ indicates a moderate or weak preference; $80-100 \%$ indicates a strong preference. A $50 \%$ preference indicates that the animal consumes equal volumes of test solution and water.

In their first experiment, using eight pigs from a single litter, the preference for saccharin solutions in concentrations of $0.25-25 \mathrm{~g} / 1$ water was determined. They found that at very low concentrations, i.e. up to $50 \mathrm{mg} / \mathrm{l}$, the animals were indifferent to the saccharin, but at higher concentrations the pigs divided into two distinct groups, with six pigs selecting saccharin in preference to water and two pigs avoiding the saccharin solution. In subsequent tests with thirty pigs from six litters, which were tested with saccharin at $0.25 \mathrm{~g} / \mathrm{l}$, the individual differences found in the first litter were confirmed, but the breakdown into preference and rejection of the solutions was not as dramatic, the mean preference being $58 \%$ (SD $19 \%$ ), with individual reactions varying from 27 to $83 \%$ preference.

In a second experiment, they examined the effect on saccharin preference of previous exposure to either sucrose solution or quinine solution. The results indicated that the pigs markedly preferred the sucrose solution (concentration $10 \mathrm{~g} / \mathrm{l}$ ) and rejected the quinine $(0.16 \mathrm{~g} / \mathrm{l})$ but these taste experiences, which lasted $5 \mathrm{~d}$, had no effect on their subsequent reaction to saccharin at a concentration of $0.25 \mathrm{~g} / \mathrm{l}$. Although the pigs showed some variation in their response to the sucrose, a high or a low preference for sucrose was no indication of how the animal would respond to saccharin. 
In a final experiment, Kare et al. (1965) examined the taste preferences of groups of young pigs to sucrose, glucose and lactose, using concentrations ranging from 5 to $4 \circ \mathrm{g} / \mathrm{l}$. The pigs preferred all three sugars to water but sucrose was more attractive than glucose or lactose and there was a tendency for the pigs to prefer more strongly the more concentrated solutions. In summarizing their experiments, these workers emphasized that there can be considerable differences in responses to specific compounds between individuals and that absolute differences in taste preferences can exist between species.

Using two-choice methods similar to those used by Kare et al. (1965), Kennedy \& Baldwin (1972) have examined the taste preferences of pigs for nutritive and non-nutritive sweet solutions over a wide range of concentrations. In one series of experiments, the pigs were individually exposed to the substances tested for $12 \mathbf{h}$ periods and care was taken to avoid position preferences. Each concentration of each substance was presented for two successive $12 \mathrm{~h}$ test periods. The different concentrations of test substances were presented initially in an ascending order of concentration, until the highest concentration was reached. This series of tests constituted an 'ascending concentration run'. After the highest concentration was reached, it was then lowered in the test sessions until the lowest concentration was reached; this was the 'descending concentration run'. It was found that there was no statistically significant difference between the results of the ascending and descending series and therefore in future experiments only one series would be necessary.

The above method, using a relatively long exposure to the taste solution of $12 \mathrm{~h}$, has the disadvantage that, when strongly preferred substances are used, the pigs may consume large volumes of fluid, which can cause significant post-ingestion effects during the preference test. This is particularly important with the more concentrated sugar solutions, where ingestion of large volumes of a hypertonic solution could dehydrate the animal and thus induce further drinking of water or the sugar solution. In order to reduce the possibility of such effects, tests were also carried out in which exposure to the test solution only lasted I h. In these shortterm tests only an 'ascending concentration run' was used.

Using the above methods of both long-term ( 12 h) and short-term ( $\mathrm{h}$ ) preference tests the following substances were tested: sucrose, glucose, sodium saccharin, sodium cyclamate and sodium chloride.

Sucrose. The preference threshold for sucrose (the concentration at which at least $60 \%$ of the total fluid intake was in the form of sucrose solution) was between 0.005 and $0.01 \mathrm{~mol} / \mathrm{l}$. At concentrations above $0.03 \mathrm{~mol} / \mathrm{l}$ all pigs displayed strong preference with very little variation. Very large volumes were consumed of the highly preferred concentrations and as much as $16 \mathrm{I}$ would be consumed in the $12 \mathrm{~h}$ test periods. The results of the short-term tests were very similar to those of the long-term tests.

Glucose. Pigs have a strong preference for glucose solutions although measurements of volumes consumed in the $12 \mathrm{~h}$ long-term tests revealed that less glucose was consumed than sucrose. This indicates that, as found by Kare et al. (1965), sucrose is the more strongly preferred sugar. A preference threshold of 
between 0.01 and $0.03 \mathrm{~mol} / \mathrm{l}$ was obtained and a strong preference was exhibited for all concentrations above $0.12 \mathrm{~mol} / \mathrm{l}$, even up to $0.6 \mathrm{~mol} / \mathrm{l}$, which was the highest concentration examined in the long-term tests. The results obtained in the short-term tests were very similar to those found in the long-term tests.

Sodium saccharin. The pigs displayed a strong preference for saccharin solutions at concentrations of 0.01 and $0.1 \mathrm{~mol} / \mathrm{l}$. The preference threshold would appear to be between 0.005 and $0.01 \mathrm{~mol} / \mathrm{l}$ but, even at the most preferred concentration the percentage preference only rose to $90 \%$. At concentrations above $0.1 \mathrm{~mol} / \mathrm{l}$ the preference rapidly fell and the pigs rejected $\mathrm{I} \cdot \mathrm{O} \mathrm{M}$-saccharin, the rejection threshold lying between $0 . \mathrm{I}$ and $\mathrm{I} .0 \mathrm{~mol} / \mathrm{l}$. The short-term and long-term results did not differ. In both short-term and long-term tests the variation between individual pigs was wide but no pigs were found which rejected saccharin over a wide range of concentrations. This finding is in contrast to those of Kare et al. (1965).

Sodium cyclamate. The behaviour of pigs towards solutions of cyclamate differed considerably from their reaction to sugars or saccharin. They seemed indifferent to any concentration up to $0.0 \mathrm{r} \mathrm{mol} / 1$ and they rejected $0 . \mathrm{I} \mathrm{M}$ cyclamate solutions. They did not show obvious preferences for any of the concentrations offered.

Sodium chloride. The pigs displayed no preference for solutions of sodium chloride and at a concentration of $\mathrm{I} \cdot 0 \mathrm{~mol} / \mathrm{l}$ they strongly rejected the solution.

\section{Operant conditioning}

By means of operant conditioning techniques it was possible to train pigs to press a switch-panel with their snouts in order to obtain small amounts of sucrose solution as a reward.

When the pigs were familiar with this task, it was possible to test them, in a special cage, using a progressive ratio schedule of reward in order to see whether they would work more consistently for strong solutions of sucrose than for weak solutions. On a progressive ratio schedule the pig pressed the panel once for the first reward, twice for the second, three times for the third and so on. The point at which the pigs paused for $30 \mathrm{~s}$ without pressing the panel was taken as the final ratio that they were motivated to reach for the particular concentration of sucrose being dispensed. It was found that the final ratios reached were consistently related to the concentrations of sucrose used as reward, and that the pigs would go to higher ratios for the more concentrated solutions. This conditioning technique was sensitive enough to detect differences in motivation for sucrose solutions of 0.03 , $0.225,0.5$ and $\mathrm{I} .0 \mathrm{~mol} / \mathrm{l}$. It is possible that similar operant techniques could be useful in detecting preferences for different foods.

\section{REFERENCES}

Aldinger, S. M., Speer, V. C., Hays, V. W. \& Catron, D. V. (1959). J. Anim. Sci. 18, 1350. Bell, F. R. (1959). F. agric. Sci., Camb. 52, 125.

Bell, F. R. \& Williams, H. L. (1959). Nature, Lond. $183,345$.

Diaz, F., Speer, V. C., Ashton, G. C., Liu, C. H. \& Catron, D. V. (1956). J. Anim. Sci. 15, 315. 
Goatcher, W. D. \& Church, D. C. (1970a). Y. Anim. Sci. 30, 777.

Goatcher, W. D. \& Church, D. C. (19706). J. Anim. Sci. 30, 784.

Goatcher, W. D. \& Church, D. C. (I970c). J. Anim. Sci. 3I, 364 .

Goatcher, W. D. \& Church, D. C. (1970d). F. Anim. Sci. 3I, 373.

Hayashi, T. (editor) (1967). Olfaction and Taste. Proceedings of the 2nd International Symposium. London: Pergamon Press.

Kare, M. R. \& Ficken, M. S. (1963). In Olfaction and Taste. Proceedings of the ist Intermational Symposium [Y. Zotterman, oditor]. London: Pergamon Prese.

Kare, M. R., Pond, W. C. \& Cambell, J. (1965). Anim. Behav. 13, 265.

Kennedy, J. M. \& Baldwin, B. A. (1972). Anim. Behav. 20, 706.

Lavue, C. G. \& Le Magnen, J. (1974). Physiol. Behav. 9, 817.

Le Magnen, J. (1971). Prog. physiol. Psychol. 4, 203.

Nelson, L. F., Hazel, L. N., Moore, A. A., Maddock, H. M., Ashton, G. C., Culberteon, C. D. \& Catron, D. V. (1953). Iowa Fm Sci. 7, part 8, p. 3.

Notzołd, R. A., Becker, D. E., Terrill, S. W. \& Jensen, A. A. (1955). F. Anim. Sci. 14, 1068.

Pfaffman, C. (editor) (1969). Olfaction and Taste. Proceedings of the 3rd International Symposium. New York: Rockefeller University Press.

Wahlstrom, R. C., Hauser, L. A. \& Libal, G. W. (1974). F. Anim. Sci. 38, 1267.

Zotterman, Y. (editor) (1963). Olfaction and Taste. Proceedings of the 1st International Symposium. London: Pergamon Press. 